\title{
Die problematiek van armoede met verwysing na onderwys, gesondheid en die gesin
}

\author{
M.C. Barnard \\ Departement Psigopedagogiek \\ Universiteit van die Oranje-Vrystaat \\ BLOEMFONTEIN
}

\begin{abstract}
The problematic nature of poverty with reference to education, health and the family

Poverty is on the increase worldwide and goes hand in hand with unemployment. In South Africa poverty is inextricably interwoven with the historical and sociocultural legacy of the largest part of the population. The causes of poverty are extremely complex and must be sought in a combination of human and structural factors. Poverty has far-reaching influence on education, health and the family life of society.

The question may be posed as to whether education has a decisive effect on the combating of poverty as such. In spite of the fact that education of a high standard is an important determinant in promoting literacy on an individual level, to improve quality of life and to develop human potential, it does not offer ready-made solutions for structural and cultural historical inequality and, this is nowhere more clearly reflected than in education.

If education proposes to make a meaningful contribution to the combating of poverty, strategies such as more effective education financing, the partial privatisation of education, greater utilisation of natural and human resources, the promotion of job creation and entrepreneurship, as well as enrichment of family life must be effected.
\end{abstract}

\section{Perspektief op die fenomeen armoede}

\subsection{Omskrywing van armoede}

Per definisie beteken armoede 'n staat van gebrek waar die individu die noodsaaklikste of minimum lewensmiddele ontbeer (Craig, s.j.:61). Armoede is dus 'n toestand van voortdurende gebrek aan lewensmiddele. Armlastigheid dui op 'n 
kroniese toestand waar mense nie net arm is nie, maar voortdurend materiële hulp moet ontvang.

Armoede is meer as net 'n gebrek aan fisiese middele - dit dui ook op 'n sekere geestesingesteldheid. 'n Armoedekultuur gaan dikwels gepaard met verskynsels soos tienerswangerskappe, vroeë skoolverlating, werkskuheid, misdaad, alkoholen dwelmmiddelafhanklikheid asook kinderverwaarlosing en -mishandeling.

Vir die doel van hierdie gesprek moet onderskeid gemaak word tussen relatiewe en absolute armoede. Eersgenoemde geval kom voor wanneer mense hulle vergelyk met andere wat materieel beter daaraan toe is en dan relatief arm voel (Kritzinger, 1990a:603; Trowler, 1989:43). Die luuidige ekonomiese insinking en hoë inflasiekoers bring baie mense se hoë lewenstandaard onder druk en skep by die middelklas die indruk van armoede. Daaruit blyk dit dat 'n persoon se persepsie van armoede nie 'n baie betroubare maatstaf vir ware armoede is nie en dikwels gekleur word deur kultureel gedefinieerde lewensbehoeftes (Townsend, soos aangehaal deur Mortimore \& Blackstone, 1982:25). Absolute armoede daarenteen dui op 'n toestand waar lewensbelangrike lewensmiddele ontbreek (Trowler, 1989:42); waar 'n toestand van wanvoeding, ongeletterdheid, siekte en hoë kindersterftes voorkom (Coetzee, 1992:295); en waar die annes reeds die stryd teen armoede verloor het. Waarvan hulle leef en hoe hulle ' $n$ bestaan maak, kan niemand verklaar nie.

\section{2 'n Christelike perspektief op armoede}

Armoede is nie 'n nuwe verskynsel nie. Die oorsprong, aard, omvang en gevolge daarvan kan teruggevoer word na die sondegebroke werklikheid wat onafskeibaar deel van die mens se lewensbestaan is. Monsma (1991:4) wys tereg daarop dat armoede een van die tragiese gevolge van die sondeval is, hoewel die oorsake daarvan nie uit die Bybel afgelees kan word nie - eenvoudig omdat die Bybel nie 'n verslaggewing van die mens se ekonomiese potensiaal verteenwoordig nie en ook nie ' $n$ ekonomiese handboek is nie. 'n Ou-Testamentiese perspektief op armoede openbaar ' $n$ besondere sensitiwiteit vir die arme en wel in terme van sy versorging, solidariteit met sy nood en die bewys van barnhartigheid aan hom (Prinsloo, 1990:18). Die Nuwe-Testamentiese etiek benadruk die innerlike bewoënheid oor die nood van die arme (Du Toit, 1990:20) en roep die Christen op tot daadwerklike aksie om dié nood te help verlig.

Vanuit 'n Christelike perspektief impliseer armoede dat die mens - algemeen gesproke - anti-normatief gehandel het op die ekonomiese lewensterrein. In plaas van verantwoordelik het hy onverantwoordelik met ekonomiese en bestaansmiddele omgegaan - dit geld vir die totale spektrum van arm tot ryk. In aansluiting hierby is daar velerlei verklarings vir armoede. Daar is veral twee uiterste standpunte, naamlik diegene wat armoede wyt aan swak mensepotensiaal en die- 
gene wat armes beskou as slagoffers van onreg en uitbuiting. Albei standpunte hou 'n element van waarheid in, dog albei misken die kompleksiteit en verweefdheid van annoede (Kritzinger, 1990b:160).

\subsection{Omvang van armoede}

In ' $\mathrm{n}$ snelveranderende wêreld is armoede as verskynsel een van die min konstante faktore. Op die keper beskou, blyk dit dat die omvang en voorkoms van armoede egter nie konstant bly nie, maar daagliks groter word (Kritzinger, 1990a: 602).

Hoewel amptelike statistiek oor die voorkoms van armoede in Suid-Afrika nie beskikbaar is nie (Eberstadt, 1988:21), kan daar op grond van verhoogde werkloosheid geredelik aanvaar word dat armoede hier te lande insgelyks besig is om toe te neem. Die Buro vir Marknavorsing (soos aangehaal deur die Volksblad, 1993-03-08, p. 3) meen dat 14 miljoen mense in Suid-Afrika tans onder die minimum bestaanspeil leef, teenoor die 13 miljoen in 1991 en 11,3 miljoen in 1988 . Die Foundation of Researcl Development (South African Institute of Race Relations, 1993:169) dui in Maart 1992 aan dat 66\% van die swart bevolking en 50\% van die totale bevolking na raming onder die broodlyn leef.

Werkloosheid neem wêreldwyd toe en skep verdere armoede. In Suid-Afrika het werkloosheid tussen 1980 tot 1990 by die ekonomies-aktiewe bevolking van $8,4 \%$ tot $14,9 \%$ gestyg. In die tydperk 1991 tot 1992 het die werkloses van 2,5 miljoen tot 5,4 miljoen toegeneem. Die omvang van werkloosheid word verder weerspieël in die feit dat tot onlangs toe slegs 90 van die 1000 toetreders tot die arbeidsmark geabsorbeer is (Coetzee, 1992:295). Die getal nuwe aansoeke vir voordele uit die werkloosheidsversekeringsfonds het tussen 1990-1991 met 44\% toegeneem en dit dui op 'n stygende tendens in werkloosheid (South African Institute of Race Relations, 1993:169).

Daar kan met 'n redelike mate van sekerheid aanvaar word dat werkloosheid in Derdewêreldlande toeneem na mate die ekonomiese groei stagneer of afneem. Die effek van werkloosheid verskil egter aansienlik in Eerste- en Derdewêreldlande. In eersgenoemde lande verlig werkloosheidsversekering die onmiddellike nood wat deur werkloosheid geskep word, terwyl werkloosheid in Derdewêreldlande vir die armes rampspoed en ellende meebring.

Grootskaalse verstedeliking het die voorkoms van armoede in stedelike gebiede aansienlik vergroot. Die afskaffing van instromingsbeheer in 1986 het 'n nuwe fase in verstedeliking ingelei. Verdere verstedeliking en die gepaardgaande armoede blyk onafwendbaar te wees. Hierdie tendens stem ooreen met navorsing wat daarop dui dat arınoede in kosmopolitiese stede toeneem (Rextroat, 1989: 70). Ten spyte van hierdie neiging word die annste van annes in die plattelandse 
Die problemaliek van armoede met verw'ysing na onderwys, gesondheid en die gesin

gebiede aangetref - veral in die huidige tuislande. Hulle is mense met baie min of beperkte vaardighede en 'n lae onderwyspeil (Anon, 1992:129). Daar is 'n noue verband tussen armoede en omgewing - nagenoeg driekwart van die ontwikkelende lande se armes kom in gebiede voor wat ekologies kwesbaar is en waar die landboupotensiaal eweneens swak is (Coetzee, 1992:296).

Die instandhouding van menslike lewe is afhanklik van die besit van voldoende lewensmiddele. Armoede bedreig die mens se lewenskwaliteit, liggaamlike en geestesgesondheid asook sy opvoedings- en onderwyspeil - juis as gevolg van die beperkte toegang tot lewensnoodsaaklike hulpbronne. Die probleem van armoede in Suid-Afrika word des te meer vererger deur die besondere sterk wanbalans tussen ryk en arm. So byvoorbeeld het die onderste $40 \%$ van die bevolking se inkomste in 1983 slegs $8 \%$ van die totale inkomste uitgemaak (Devereux, 1983:37). Met verwysing na annoede waarsku Van Coller (1990:7-8): "No society can survive with the inequality of incomes that characterises South Africa at the present." Volgens Wilson (1991:44) is Suid-Afrika die land met die hoogste ongelykheid in inkomste tussen ryk en arm van 57 lande wat deur die "coefficient of inequality" van Geni gemeet is.

Armoede in die Suid-Afrikaanse konteks is onlosmaaklik verweef met die geskiedkundige en sosiokulturele erfenis van die grootste deel van die bevolking Dit is egter onwys om die netwerk van oorsaaklike faktore van armoede mis te kyk. Wilson (1991:44) waarsku teen die neiging om armoede aan slegs 'n enkele sisteem soos apartheid, kapitalisme, sosialisme of oorbevolking te wyt. Hierdie en ander sisteme staan immers in interaksie met mekaar. In hierdie verband konkludeer Gahamya (1991:57) dat een van die wanopvattings van die teologie van bevryding geleë is in die feit dat die armes tot een kategorie beperk word, naamlik diegene wat materieel benadeel is deur die onderdrukking en uitbuiting deur rykes en invloedrykes. Die oorsake van armoede is ' $n$ komplekse aangeleentheid en moet eerder gesoek word in 'n kombinasie van menslike en strukturele faktore (Kritzinger, 1990a:17).

\section{Armoede en onderwys}

\subsection{Die effek van onderwys op geletterheid en armoede}

Dat kwaliteitonderwys 'n belangrike determinant is om op individuele vlak geletterdheid te bevorder, lewenskwaliteit te verbeter en menslike potensiaal te ontwikkel, is nie te betwyfel nie. Die aanname dat onderwys die sleutel is tot die opheffing van armoede en ongeletterdheid is egter 'n oorvereenvoudiging van 'n komplekse aangeleentheid en 'n oorwaardering van onderwys in die algemeen. 
Onderwys as sodanig bied nie klinkklare oplossings vir struktuur-gegenereerde annoede en sosiale verwaarlosing nie. Wanneer 'n onderwysstelsel rigied en onbuigsaam bly, is dit geneig on daardie strukturele en kultuurhistoriese ongelykheid wat aanvanklik teenwoordig was, te weerspieël. In hierdie verband wys die Australiese Regeringskommisie van ondersoek na arnoede daarop dat die skool in sy huidige vorm weinig meer as 'n sorteringsmeganisine is wat die bestaande verspreiding van die status quo in stand hou (Nasson, 1990:94). Vandaar moontlik Nasson (Nasson \& Samuel, 1990:94) se betoog dat die idee dat onderwys die potensiaal het om ongelykhede in rykdom, voorspoed en geleenthede reg te stel, tans 'n geloofwaardigheidskrisis ondervind.

Die Suid-Afrikaanse onderwysstelsel met sy sterk ideologiese ondertoon - hoe goed ook al bedoel - is 'n goeie voorbeeld van die instandhouding van 'n strukturele en kultuurhistoriese ongelykheid. In hierdie verband meen Gildenhuys en Le Roux (1993) dat skole en onderwysstelsels in Suid-Afrika nie toereikend voorsien in die behoeftes van die arnoedkultuurkind nie. Om egter te beweer dat ' $n$ struktuurverandering in die onderwysstelsel arnoede gaan hokslaan, is 'n oorvereenvoudiging van 'n baie komplekse aangeleentheid en 'n oorwaardering van onderwys in die algemeen.

Statistiek toon aan dat verpligte primêre onderwys nie 'n effektiewe instrument is om ongeletterdheid in ontwikkelende lande te besweer nie (Mutava, 1988:335). Hierdie toedrag van sake kan toegeskryf word aan die vinnige groei in populasie, hoë uitvalsyfer op skool en geldelike en mannekragbeperkinge. As die sosio-ekonomiese posisie van talle verarnde leerlinge in Suid-Afrika in ag geneem word, kan geredelik aanvaar word dat hulle - vanweë die hoë koste van onderwys in 'n nuwe onderwysbedeling - dit heelwaarskynlik nie sal kan bekostig om “... voltyds tot sekondêre skole toe te tree nie" (Theron, 1992:36-37).

\subsection{Die effek van onderwys op die herverdeling van rykdom}

Onderwys op sigself kan nie daarin slaag om die herverdeling van rykdom te bewerkstellig nie (Nasson \& Samuel, 1990:2). Robinson (1976:10) meen ook dat hervorming in die onderwysstelsel per se min effek het op die lewenstandaard van armes as 'n groep. Die impak van formele onderwys op die ekonomiese ontwikkeling van 'n land is kleiner as wat algemeen aanvaar word (Claassen, 1992: 108). Toereikende onderwys kan egter 'n belangrike en betekenisvolle bydrae lewer tot die verbetering van die individu se lewenskwaliteit en -standaard.

Navorsing (Nasson, 1990:90-9l) dui daarop dat 'n waardering van die waarde van onderwys om ongelykheid in inkomste in die Derdewêreld te laat krimp 'n redelike pessimistiese beeld skep. Hoewel Ceylon se onderwysvoorsiening aansienlik uitgebrei is en geletterdheid as gevolg daarvan merkbaar verhoog het, was daar in die ooreenstemmende periode slegs 'n skamele verhoging in die per kapita 
produktiwiteitskaal, terwyl die inkomste ook redelik konstant gebly het. In die tagtigerjare het Zimbabwe se massiewe verhoging in staatsbesteding op sosioekonomiese dienste - onder andere die onderwys - ten koste van belegging en werkskepping plaasgevind. Dit het natuurlik 'n verskynsel teweeggebring wat op sigself weer 'n probleem is (Anon, 1992:123).

Benewens die voordeel van algemene verhoogde geletterdheid in sommige ontwikkelende lande is daar geen afdoende bewys dat onderwys bydra tot 'n verhoogde inkomste nie. Rama, soos aangehaal deur Nasson (1990:91), sê in hierdie verband dat dit makliker is om toegang tot onderwys op alle vlakke te verkry as tot mag en rykdom. Jencks (soos aangehaal deur Byrne et al., 1975:168-169), gaan hiermee akkoord wanneer hy dit kategories stel dat 'n regverdige verdeling in onderwys min impak sou hê op die gevolglike verskil in inkomste by daardie kinders wanneer hulle volwasse is. Claassen (1992:108) skryf die beperkte invloed van onderwys op armoede toe aan die feit dat dit nie die kind vir die arbeidsmark voorberei nie.

\subsection{Die effek van armoede op opleiding}

Die beperkende invloed van armoede op onderwys hou verreikende gevolge vir opleiding in, want hoe laer die algemene vlak van geletterheid is, hoe laer is ook die effek van opleiding. Die hoë persentasie ongeletterde persone $-8,3$ miljoen in Suid-Afrika - plaas spanning op die reeds swak ondersteunende band tussen onderwys en opleiding (Coetzee, 1992:309). Dit skep weer 'n onnodige las op die verskaffers van opleiding om die agterstand reg te stel en vra spesifieke staatsondersteuning wat 'n verdere las op die begroting plaas.

\subsection{Die effek van armoede op die kind se leeromgewing}

Armoede is 'n belangrike rolspeler by die skep van milieugestremdheid en deprivasie. In hierdie verband kan deprivasie gedefinieer word as daardie omstandighede wat die kind verhinder om sy potensiaal na behore te verwesenlik. Hierdie omstandighede manifesteer in armoede, emosionele verarming, persoonlikheidsversteurings, swak opvoedingstandaard, depressie en wanhoop. Dit bring mee dat baie van die leerervaring op skool vir die milieugestremde kind verlore gaan omdat hy in sy opvoeding sekere ervarings en kwaliteite van begeleiding moes ontbeer (Garbers, 1980:51). Swak voorbereiding om die eise van die skool te kan akkommodeer, lei dikwels tot leermislukking wat weer 'n negatiewe terugvoersiklus tot gevolg het.

Die sosio-kulturele, perseptuele, kognitiewe en taalagtergrond wat die verarmde en dikwels verwaarloosde skoolbeginner het, rugsteun hom nie vir die eise van aanvangsonderwys nie. Die skoolorganisasie en kurrikulum is nie afgestem op 
die gedepriveerde kind se behoeftes nie en beklemtoon dikwels sy agterstand in plaas daarvan om dit op te hef. Die skoolkurrikulum erken nie die noue verband tussen die gedepriveerde se kultuur en die realiteite van sy sosiale leefwêreld nie. Sonder 'n ondersteunende opvoedingsmilieu is kompenserende onderwys se rykwydte beperk (Robinson, 1976:50).

Die swak werksomstandighede van armoedige ouers het 'n indirekte effek op hul kinders se skoolervaring. Sulke ouers bestee baie tyd om na en van die werk te pendel, werk lang ure en kom moeg tuis. Armoede dwing moeders om te gaan werk en laat dikwels ernstige leemtes by die versorging van die kinders. Dit beperk die ouer en kind se saamwees. Die magteloosheid wat die ouer in sy werksituasie beleef, word dikwels ook op die gesinslewe oorgedra (Mortimore \& Blackstone, 1982:26).

Armoede beïnvloed die kind se onderwys ook op 'n direkte wyse. Geld word selde aan boeke, opvoedkundige hulpmiddels en uitstappies bestee, die ouer toon weinig belangstelling in die kind se skoolwerk en van aanmoediging en motivering is daar weinig sprake. Robinson (1976:20) verwys na navorsing wat aantoon dat minderbevoorregte kinders ook swakker presteer in lees en rekenkundige toetse. Swak skolastiese prestasie lei dikwels tot stokkiesdraai en ander gedragsprobleme

\subsection{Die effek van armoede op onderwysfinansiering}

Armoede skep 'n finansiële krisis vir die onderwyssituasie in Suid-Afrika. Hoewel die regering hom reeds in 'n Witskrif (RGN, 1983) tot gelyke onderwysgeleenthede vir elke inwoner verbind het, het die onbeheerde bevolkingsaanwas en swak ekonomiese groei die staat in hierdie voomeme aan bande gelê. Teenoor die bevolkingsaanwas van $2,13 \%$ het die bruto nasionale inkomste vir die ooreenstemmende tydperk slegs met 1,5\% per jaar toegeneem (Niemann, 1992:362). In 1990 het die totale onderwysbesteding $22 \%$ van die staatsbegroting uitgemaak. In die boekjaar 1992/93 het onderwysuitgawes in Suid-Afrika - die tuislande uitgesluit - met $11 \%$ toegeneem in vergelyking met dié van 1991/92 (South African Institute of Race Relations, 1993:575). Die staat kan kwalik 'n groter deel van die Bruto Binnelandse Produk aan onderwys afstaan (Kok, 1992:140). Om die huidige toename in die bevolkingsgroei te absorbeer, sal die ekonomiese groei met nagenoeg $3 \%$ per jaar moet toeneem. As die staat onderwyspariteit tussen die verskillende bevolkingsgroepe wil bereik, sal hy $52 \%$ van sy totale begroting aan onderwys moet bestee (Oosthuizen, soos aangehaal deur Niemann, 1992: 362). Hierdie doelwit is uit die aard van die saak nie haalbaar nie. 
Die problematiek van armoede met verwysing na onderwys, gesondheid en die gesin

\section{Armoede en gesondheid}

Armoede, swak lewensomstandighede en onvoldoende voeding het tot gevolg dat 'n kind 'n groter kans staan om prematuur gebore te word, om 'n ondergewig baba te wees en om nie die eerste lewensjaar te oorleef nie (Papalia \& Olds, 1989:195). Die persentasie kinders wat nie geïmmuniseer is nie, is ook by die lae inkomstegroep aansienlik hoër as wat dit by die hoë inkomstegroep die geval is. Die voorkoms van kindersterftes hou dikwels verband met armoede. Mij en Vallablijee (1990:122) meen dat gemeenskaps- en omgewingstoestande 'n oorheersende effek het op die gesondheid van die bevolking en daarom verg dit enorme verbetering.

Navorsing (Balian de Tagtachian, 1990:43) dui daarop dat gesinne met die minste lewensmiddele neig om die meeste kinders te hê. Swak lewensomstandighede, swak gesondheid en beperkte onderwys gaan dus hand aan hand en staan in 'n nou verband met 'n gebrek aan inkomste. In hierdie armoedige gemeenskappe is die voorkoms van tienerswangerskappe en verwaarloosde kinders ook soveel hoër. Tienerswangerskappe lei nie slegs tot ' $\mathrm{n}$ herhaling van armoede nie, maar ook tot ' $n$ intensivering daarvan. Onder nornale onstandighede verbeter voeding met verhoogde inkomste. Die omgekeerde is eweneens waar: daar is 'n sekere inkomstedrumpel waar armoede (broodsgebrek) tot hongersnood (bestaansgebrek) oorgaan.

In oorbevolkte arm gesinne is die voorkoms van wan- en ondervoeding hoog. Nagenoeg 3,2 miljoen mense - insluitend 1 miljoen kinders - lei aan ernstige wanvoeding (Anon, 1992:129). In sulke gevalle kom liggaamlike, verstandelike en geestesagterstande meer algemeen by die kinderbevolking voor. Ondervoeding en aanverwante siektes beïnvloed die leervernnoë van die kind. 'n Vermeerdering in kindertal lei tot ' $\mathrm{n}$ vermindering in die kwaliteit van die kind se lewe (Becker \& Lewis, soos aangehaal deur Hossain, 1990:264). Dit plaas 'n bykomende las op gemeenskapsgesondheid wat reeds steier onder die hoë koste van mediese dienste. Die kostestruktuur van mediese versorging is vandag een van die kwellendste sosiale bekommernisse (Allegrante, 1988:364).

Onderwys en opvoeding word as 'n belangrike determinant beskou om familiegrootte te verminder (Hossain, 1990:264) en daardeur gesondheidsorg te verbeter. 'n Mens kan nie aan gesondheid dink sonder om oor gesinsbeplanning te praat nie. Folb (1990:120) meen dat hervorming in gesondheidsdienste in Suid-Afrika slegs kan slaag as dit hand aan hand gaan met die verbetering in onderwys, maatskaplike sekuriteit, ontwikkeling van die infrastruktuur en werkskepping. 'n Hoë bevolkingsaanwas het die effek dat dit die onderwys laat stagneer - in baie gevalle selfs laat agteruitgaan - en 'n aansienlike deel van die bevolking sonder die minimum onderwys laat. Die groot persentasie jeugdiges in die Suid-Afrikaanse 
populasie beteken dat al sou die vrugbaarheidspeil daal tot slegs 'n vervangingskaal, sal bevolkingsgroei nogtans toeneem (Anon, 1992:130).

Hoewel die opheffing van armoede sekerlik 'n belangrike bydrae sal lewer tot gesondleidsbevordering en siektevoorkoming, moet steeds rekening gehou word met die feit dat die mens waarskynlik sy grootste vyand is as dit by gesondheid kom. Wat die mens eet, of hy oefening doen en hoeveel hy rook en drink, het baie te make met die vraag of hy 'n maksimum lewensverwagting en 'n goeie lewenskwaliteit gaan hê (Allegrante, 1988:364).

\section{Armoede en die gesinslewe}

Die gesin is 'n sosiale eenheid wat voor 'n reeks ontwikkelingstake te staan kom. 'n Belangrike ontwikkelingstaak is om vir die kind 'n gesinsmilieu te skep waarin sy basiese liggaanlike, emosionele, sosiale, kulturele en geestelike behoeftes bevredig kan word.

In die normale gang van sake ondervind gesime die een of ander tyd probleme met aspekte soos gesinsverhoudinge, die opvoeding van kinders, gesondheid, voorsiening in lewensmiddele en wedywering met die buitewêreld. Gesinne wat kultureel, geestelik en materieel toereikend toegerus is, kan alledaagse lewensprobleme normaalweg die hoof bied. Waar ' $n$ armoedekultuur egter heers, is die gesin vasgevang in die uitsigloosheid van sy milieu en kom gesinslede se basiese behoeftes soos voedsel, kleding, huisvesting, veiligheid, gesondheid, werksgeleentheid, onderwys en ontspanning ernstig in die gedrang. Dit plaas groot stres op die gesin - veral dié wat armoede geërf het (Papalia \& Olds, 1989:194).

Armoede maak die gesin sosiaal kwesbaar, want dit verhinder die gesinslede se koppeling met die sosiale en kulturele buitewêreld. Dit bemoeilik die kind se sosiaal-maatskaplike oriëntasie en dompel hom dikwels in ' $n$ identiteitskrisis. Emosionele onstabiliteit in die gesin word verhoog deur stresfaktore soos woningnood, werkloosheid en onveiligheid. Gesinslede wat op gespanne voet verkeer, ervaar dikwels interpersoonlike verhoudingsprobleme, kommunikeer swak en ontoereikend en ruil negatiewe gevoelens soos aggressie en verwerping uit.

Armoede maak die gesin opvoedkundig kwesbaar. Die vader en moeder is dikwels afwesig weens werkverpligtinge. Kinders word aan hulself oorgelaat en word die prooi van ongesosialiseerde portuurgroepe waar gewelddadigheid, vernielsugtigheid en losbandigheid aan die orde is

\section{Toekomsperspektief}

Daar is nie kitsoplossings of ' $n$ algemeen toepasbare model vir die tergende probleem van annoede nie. 'n Nasionale strategie en die koördinering van die totale 
Die problematiek van armoede met verwysing na onderwys, gesondheid en die gesin

Suid-Afrikaanse samelewing is nodig om dié knellende probleem te ondervang. Die staat, kerk, privaatsektor, skool, gesin en elke individu moet in hierdie verband betrek word.

Met besondere verwysing na onderwys, gesondheid en die gesin kan die volgende breë strategieë moontlik oorweeg word:

* Die staat se beperkte bronne vir onderwysfinansiering sal so effektief en doelmatig moontlik aangewend moet word. Dit impliseer onder andere 'n meer vaartbelynde en kostebesparende onderwysstruktuur en 'n beperking op die staat se finansiële verantwoordelikheid ten opsigte van basiese onderwys (Claassen, 1992:101). Daar is min ruimte in die staatsbegroting vir 'n verdere verhoging in die verhouding van die bronne wat aan onderwys toegesê kan word (Simkins, 1990:166; Berger, 1990:146). Die uitdaging wat werkskepping, onderwys en gesondheid aan die landsekonomie stel, is toenemend skrikwekkend.

* Die ideaal van gelyke onderwysstandaarde vir almal in ' $n$ land met 'n multikulturele bevolking soos Suid-Afrika is nie haalbaar nie - dog wel gelyke onderwysgeleenthede. Elke gemeenskap behoort derhalwe toegelaat te word om self die beste onderwysstandaard vir sy kinders te vind. Dit bring mee dat die staat sy verantwoordelikheid ten opsigte van onderwys sal moet herdefinieer (Kok, 1992:144). 'n Beleid van gedeeltelike privatisering vir onderwys waarin die staat die verantwoordelikheid vir minimum onderwysfasiliteite soos geboue, salarisse, kontrole en kurrikula aanvaar en die gemeenskap verantwoordelik is vir lopende koste en die uitbreiding van geriewe, blyk 'n moontlike oplossing te wees. Die finansieringslas vir onderwysvoorsiening sal wyer as die staatsinkomstebron versprei moet word na die individu, die ouer, die breë gemeenskap en die ekonomiese sektor (Niemann, 1992:363).

* 'n Noodsaaklike prioriteit is die ontwikkeling van ekonomiese strategieë wat daarop gemik is om die land se rykdom aan natuurlike en menslike hulpbronne tot 'n surplus te genereer. Dit impliseer 'n markgerigte ekonomiese stelsel sodat dit vir alle bevolkingsgroepe moontlik is om in die ekonomiese vooruitgang te deel (Niemann, 1992:363). 'n Kernvraag is hoe die verband tussen onderwyshervorming en produktiwiteit beslag kan kry. Die koppeling tussen onderwys en werkgeleentheid asook werkskepping - sonder om onderwys eensydig op die arbeidswêreld te rig - is ' $n$ diepgevoelde behoefte. Relevante onderwys kan 'n substansiële bydrae lewer tot die ontwikkeling van gemeenskappe se inisiatief en potensiaal sodat die armes op 'n verantwoordelike wyse die pad uit anmoede kan vind deur die verskaffing van geleenthede (Van Coller, 1990:7-8). Die klem moet val op dit wat die armes het: arbeid en die benutting daarvan. 
M.C. Barnard

* Die misbruik van onderwys vir magsmonstering is 'n gevaarlike spel. 'n Politieke drukgroep wat sy kinders vir revolusie gebruik, het weinig hoop op 'n sinvolle en bestendige politieke toekoms. 'n Poging moet aangewend word om die onderwys van 'n oorverhitte politieke basis te ontkoppel. Dit is veel makliker om politieke onafhanklikheid te bekom as om 'n nuwe onderwysstelsel te konstrueer. Onderwys is slegs veilig in die hande van opvoedkundiges en onderwyskundiges wat die belange van die kind op die hart dra.

* Hoë kwaliteit voorskoolse programme verhoog die vooruitsigte vir sosioekonomiese benadeelde leerlinge en dien as 'n effektiewe langtermynbelegging teen sosiale probleme wat met armoede gepaard gaan (Weikart, 1992). Die voorskoolse onderwyservaring sal medebepaal in welke mate die kind sal baat by en sukses sal behaal by formele onderwysgeleenthede. Die skolasties-georiënteerde vaardighede wat die armoedekultuurkind voorskools verwerf, moet in die primêre skoolprogram ingeoefen en versterk word. Indien wel, sal dit akademiese vordering vir die armoedekultuurkind in die primêre skool moontlik maak.

* Onderwys en opleiding moet nie net vaardighede van die een of ander aard aanleer nie, maar moet ook afgestem word op werkskepping deur die bevordering van entrepreneurskap. Daar moet egter gewaak word teen te vroeë spesialisasie, want in ontwikkelende lande het vroeë spesialisasie op 'n swak algemene onderwyspeil min vrug opgelewer (Simkins, 1990:167). Dit is verder noodsaaklik dat die komplementêre verband tussen onderwys en opleiding raakgesien en ten beste benut word. Waar onderwys 'n breë algemene geletterdheidspeil met die oog op sosiale, politieke en kulturele verrigtinge ten doel het, streef opleiding daarna om mense toe te rus met kennis en vaardighede wat op ekonomiese verrigting gemik is. Dit wil voorkom of hoër vlakke van onderwys wat gekoppel is aan opleiding 'n hoër inkomste tot gevolg het (Coetzee, 1992:300) en dus armoede tot 'n mate kan bolwerk. Verandering in die onderwysbeleid sal verder ook moet tred hou met die landelike en tradisionele sektore van die ekonomie om 'n betekenisvolle bydrae te lewer tot die voorkoming van annoede - veral wat die platteland betref.

* Om armoede doelınatig te beveg, sal daar op die gesin gefokus moet word. Gevallestudies toon dat die armoedesindroom sy beslag vind in die gesin en daarvandaan uitkring na groepe gesinne wat weer armoedige gemeenskappe vorm. Op hierdie wyse word armoede oorgedra van een geslag na die ander en ontstaan ' $n$ armoedekultuur. Die beste invalspoort is dus die gesin - ook wat die onderwys betref. In hierdie verband word aan volwassene-onderwys gedink. Dit behels egter meer as bloot net geletterdheidsprogramme dit sluit ook ouerbegeleidings- en opheffingsprogramme in wat al die fasette van persoons- en gesinsverryking omvat. Die fokuspunt is die vrou en moe- 
Die problematiek van armoede met verwysing na ondenwys, gesondheid en die gesin

der omdat sy tradisioneel meer betrokke is by die opvoeding van die kinders.

\section{Samevatting}

Armoede is een van die knellendste probleme wat Suid-Afrika in die gesig staar. Armoede destabiliseer die politiek, dit plaas 'n ondraaglike las op die landsekonomie, dit ondermyn basiese onderwys en opleiding, dit lê die gesondheidsdienste aan bande en dit skep velerlei sosio-maatskaplike probleme.

Daar is geen kitsresep of towerformule vir die probleem van armoede nie. Die hoë premie wat op onderwys geplaas word om armoede op te hef, is 'n oorwaardering van die reikwydte en trefkrag van onderwys in die algemeen. Nietemin kan aanvaar word dat ' $n$ verantwoordbare onderwysstelsel - wat gerig is op die opheffing van landsburgers en die vestiging van 'n gesonde landsekonomie saam met ander strategieè 'n betekenisvolle bydrae kan lewer om armoede in bedwang te hou. Dit behels 'n duur, veeleisende en nougesette langtermynopvoedings- en vormingstaak. Slegs die tyd sal leer of Suid-Afrika hierdie toets kan slaag.

\section{Bronnelys}

ALLEGRANTE, J.P. 1988. Potential Uses and Misuses of Education in Health Promotion and Disease Prevention. Teachers College Record, 86 (2):359-373

ANON. 1992. Gearing up for the Long Road. The Challenge of Poverty in South Africa, Optima, 38(3): 122-136.

BALIAN DE TAGTACHIAN, B. 1990. Poor Families in Latin America. Unisa Latin America Report, 6 (2): 40-46.

BERGER, P.L. 1990. A System That's to the Credit of Us All - Welfare and Equality - the International Experience. Optima, 37(4):142-147.

BYRNE, D., WILLIAMSON, B. \& FLETCHER, B. 1975. The Poverty of Education: a Study in the Politics of Opportunity. London : Martin Robertson.

CLAASSEN, J.C. 1992. Economic Perspectives on a New Educational Dispensation. Publikasiereeks van OVSA, 23:99-116.

COETZEE, D. 1992. Training as an Instrument to Combat Poverty and Unemployment: A National and International Perspective. Development South Africa, 9(3): 295-315.

CRAIG, G.J. s.j. Human Development. Amherst : The University of Massachusetts.

DEVEREUX, S. 1983. South African Income Distribution. Saldru Working Paper, 51.

DU TOIT, A. 1990. Wat sê die Nuwe Testament oor armoede? Sendingblad, 26(4):20-22.

EBERSTADT, N. 1988. Poverty in South Africa. Optima, 36(1):20-30.

FOLB, P.I. 1990. A Time to Choose. Suid-Afrikaanse Tydskrif vir Mediese Joernaal, 78(3): 120-121.

GAHAMYA, E. 1991. The Scourge of Poverty in Africa: What Should Be the Christian Response. Potchefstroom : PU vir CHO. (IRS-studiestuk, F1, no. 287.)

GARBERS, J.G. 1980. Vroee skoolverlating in die grootstad. Durban : Butterworth.

GILDENHUYS, F.P. \& LE ROUX, J. 1993. Die opvoedings- en onderwysimplikasies van 'n armoedekultuur. Pedagogiekjoernaal, 14(2):32-44. 
M.C. Barnard

HOSSAIN, S.I. 1990. Interrelations between Child Education, Health, and Family Size: Evidence from a Developing Country. Economic Development and Cultural Change, 38(4):763-781

KOK, J.C. 1992. Die staat en onderwysstandaarde. Publikasiereeks van OISA, 23:139-145

KRITZINGER, J.J. 1990a. Die Kerk en armes in Suid-Afrika. Ned. Geref. Teologiese Tydskrif, 31(4):602-620.

KRITZINGER, J.J. 1990b. Wat veroorsaak armoede? Die Sendingblad, 26(4):16-17

MIJ, D. \& VALLABHJEE, KN. 1990. Health in a Post-Apartheid South Africa. SuidAfrikaanse Mediese Joernaal, 78 (3):122-123.

MONSMA, G.N. 1991. Biblical and Theological Perspectives on Poverty. Potchefstroom : PU vir CHO. (IRS-studiestuk, FI, no. 287.)

MORTIMORE, J. \& BLACKSTONE, T. 1982. Disadvantage and Education. London Heinemann Educational Books.

MUTAVA, D.M. 1988. Forty Years of Struggle against Illiteracy: the Zambian Case. Prospects, 18(3):335-349.

NASSON, B. 1990. Education and Poverty. (In Nasson, B. \& Samuel J. eds. Education From Poverty to Liberty. Cape Town : David Philip. p. 88-108.)

NASSON, B. \& SAMUEL, J eds. 1990. Education: From Poverty to Liberty. Cape Town David Philip

NIEMANN, G.S. 1992. Onderwysstandaarde: Finansies as parameter. Publikasiereeks van OVSA, 23:360-371

PAPALIA, D.E. \& OLDS, S.W. 1989. Human Development. New York: McGraw-Hill

PRINSLOO. W.S. 1990. Die arme in die Ou Testament. Sendinghlad, 26(4): 18-19

RAAD VIR GEESTESWETENSKAPLIKE NAVORSING (RGN). 1983. Witskrif oor onderwysvoorsiening in die Republiek van Suid-Afrika. Pretoria : Staatsdrukker.

REXTROAT, C. 1989. Economic Transformation, Family Structure and Poverty Rates of Black Children in Metropolitan Areas. The American Economic Review, 79(2):67-70

ROBINSON, P. 1976. Education and Poverty. London: Methuen.

SIMKINS, C. 1990. Balancing the Scales - A Perspective for Combatting Poverty. Optima, 37(4):164-169.

SOUTH AFRICAN INSTITUTE OF RACE RELATIONS. 1993. Race Relations Survey Johannesburg : South African Institute of Race Relations

THERON, M.J. 1992. Minimum standaarde vir primêre onderwys as basisonderwys in 'n nuwe onderwysbedeling. Publikasiereeks van OVSA, 23:236-47.

TROWLER, P. 1989. Investigating Health, Welfare and Poverty. London : Unwin Hyman.

VAN COLLER, D.L. 1990. Socio-Economic Upliftment in South Africa. (hild Welfare, 16(2):7-8.

WEIKART, D.P. 1992. The Long-Term Benefits of Pre-School Education. Educamus. 38 (4): $15-16$

WILSON, F. 1991. Uprooting Poverty. Potchefstroom : PU vir CHO. (IRS-studiestuk, FI, no. 287.) 
